\title{
Unlocking cartography in the United Nations in the era of Data for action
}

\author{
Ayako Kagawa $^{\mathrm{a}, *}$ \\ ${ }^{a}$ United Nations Interim Force in Lebanon (UNIFIL), kagawa@un.org \\ * Corresponding author \\ Author is an officer of the United Nations Interim Force in Lebanon (UNIFIL), Naqoura, Lebanon. \\ The views expressed are those of the author and do not necessarily reflect those of the United Nations. (ST/AI/189/Add.6/Rev.5)
}

Keywords: United Nations, Data Strategy, Geospatial Strategy, evidence-based decision making, cartographic communication

\begin{abstract}
:
As structural organisational reform took place and settled, the Secretary-General of the United Nations has called upon the Organisation to focus on building data, digital technology and innovation capabilities of the Organisation to meet the needs of the international community in the $21^{\text {st }}$ century. In May 2020, the United Nations Secretariat launched the "Data Strategy of the Secretary-General for Action by Everyone, Everywhere: With Insight, Impact and Integrity" where he shared the vision of "building a whole-of-UN ecosystem that unlocks our full data potential for better decisions and stronger support to people and planet".

In meeting with the vision, different communities within the Organisation are trying to align their data needs and mandates and operations of the United Nations. This paper will explore how these data related activities by the diverse data related communities are changing the Organisation's evidence-based decision making process and how this impacts the geospatial data and cartographic demands of the Organisation, and whether this paradigm shift will bring a need to revisit cartographic communication theory discourse.
\end{abstract}

